\title{
Brazilian hepatitis B vaccine: a six-year follow-up in adolescents
}

\author{
Kamilla Vêncio Frauzino Alexandre', Regina Maria Bringel Martins², \\ Márcia Maria de Souza ${ }^{1}$, Isolina Maria Xavier Rodrigues ${ }^{3}$, Sheila Araujo Teles ${ }^{1 /+}$ \\ ${ }^{1}$ Faculdade de Enfermagem ${ }^{2}$ Instituto de Patologia Tropical e Saúde Pública \\ ${ }^{3}$ Hospital das Clínicas, Universidade Federal de Goiás, Goiânia, GO, Brasil
}

\begin{abstract}
The protective anti-HBs titres were examined six-year post-immunisation with the Brazilian recombinant hepatitis $B$ vaccine. After the primary vaccination, all adolescents $(n=89)$ responded with protective anti-HBs titres and had a geometric mean titre (GMT) of 4031.8 mIU/mL. In 2010, 94.5\% maintained protective anti-HBs (>10 mIU/mL) antibodies, with a GMT of $236.0 \mathrm{mIU} / \mathrm{mL}$. A positive correlation was observed between the anti-HBs titres after the primary vaccination and the titres at the six-year follow-up $(p<0.01)$. Eleven subjects showed anti-HBs titres suggestive of a natural booster. Prostitution and tattoos/piercings were marginally associated with natural boosters in the multivariate analysis. This study showed the first data on anti-HBs persistence following the Brazilian hepatitis $B$ vaccine in sexually active individuals and highlights its effectiveness in the medium term.
\end{abstract}

Key words: hepatitis B vaccine - adolescents - follow-up

To date, approximately 350,000-400,000 people worldwide are chronically infected with hepatitis B virus (HBV), resulting in yearly mortality rates of approximately one million due to disease-associated complications. In addition, most new cases occur among young adults (Romano et al. 2011).

The hepatitis $B$ vaccination has been used since the 1980s. The first hepatitis B vaccines contained HBsAg particles obtained from the sera of HBV carriers; these vaccines were then replaced by DNA recombinant vaccines (Beasley 2009). Initially, two laboratories produced recombinant hepatitis B vaccines using Saccharomyces cerevisiae as an expression system to obtain the HBsAg particles (Shouval 2003). These vaccines are highly immunogenic and safe and induce protection against hepatitis B infections for at least 20 years (But et al. 2008, Poorolajal et al. 2010). Today, highly immunogenic hepatitis B vaccines comprising recombinant $\mathrm{HBsAg}$ generated using different yeast expression systems are available, but there are no data on anti-HBs persistence (Ioshimoto et al. 1999, Hieu et al. 2002, Vijayakumar et al. 2004, Zhang et al. 2011).

The Brazilian recombinant hepatitis B vaccine was introduced in the National Immunisation Program in early 2000 . This vaccine is produced by Butantan Institute and the recombinant antigen is expressed using the Hansenula polymorpha yeast cell expression system (Ioshimoto et al. 1999). This system is less expensive and more productive than $S$. cerevisiae expression systems, thereby reducing the price of individual vaccine doses (Hieu et al. 2002).

+ Corresponding author: sheila.fen@gmail.com

Received 22 February 2012

Accepted 16 August 2012
Between 2003-2004, our research group studied 664 adolescents who were 11-19 years of age and found a global HBV prevalence rate of 5.9\% (ranging from 2.4\% among adolescents who were $12-13$ years of age to $17.3 \%$ among adolescents who were 18-19 years of age). Furthermore, the multivariate analysis showed that older adolescents (16-19 years old) had a 3.6-fold greater chance of being exposed to HBV than younger individuals, suggesting that lifestyle changes were associated with risk behaviours that increased their chances of acquiring hepatitis B infections. A total of 170 susceptible adolescents were vaccinated with the Brazilian recombinant hepatitis B vaccine $(20 \mu \mathrm{g})$ at zero, one and six months as recommended in the state of Goiás (GO) (Central Brazil) at the time. All participants developed protective anti-HBs following the administration of a complete vaccine regimen, resulting in a geometric mean titre (GMT) of $4.344 \mathrm{mIU} / \mathrm{mL}$ (Oliveira et al. 2006). This scenario represented a unique opportunity to investigate the effectiveness of the Brazilian HBV vaccine six years after the primary vaccination in a target group.

Recruitment occurred from September-December 2010. Individuals who had received booster doses during the follow-up (2006-2010) were excluded. The recruitment strategy consisted of contacting the potential participants by telephone to schedule a date, time and place for an interview. If this approach was unsuccessful, the researchers searched the area surrounding the participant's former residence to gather information about the participant from relatives, neighbours or current residents.

When the participants were identified, they were interviewed at their residence by a trained nurse. Data regarding the risk factors for acquiring HBV infections during the follow-up, such as homosexual practices, condom use, sexually transmitted diseases, number of sexual partners, prostitution, prison, use of illicit drugs and tattooing/body piercing were obtained and blood samples were collected. 
The collected blood samples were examined quantitatively following the primary vaccination for the presence of anti-HBs using the Microparticle Immunoenzymatic Test (AxSYM ${ }^{\circledR}$ Ausab $^{\circledR}$, Abbott, Germany) and the anti$\mathrm{HBc}$ marker using Hepanostika Uni-Form for anti-HBc (Hepanostika Uni-form, bioMérieux, Boxtel, The Netherlands). The anti-HBs titres were expressed in international units (IUs) according to the manufacturer's instructions, using the World Health Organization standard reference serum provided in each kit. Anti-HBs titres $<10 \mathrm{mIU} / \mathrm{mL}$ were considered to be non-protective and anti-HBs titres $\geq$ $10 \mathrm{mIU} / \mathrm{mL}$ were considered to be protective. A natural booster resulting from HBV exposure post-vaccination was defined as an increase in the anti-HBs titre two-fold greater than the previously obtained values.

The statistical analyses were performed using SPSS 16.0. The GMT of the anti-HBs titres was calculated with a $95 \%$ confidence interval (CI). The correlation of the antibody titres was assessed using the non-parametric Spearman's test. The chi-square test and Fisher's exact test (categorical variables) were used to compare variables and evaluate the association between a "natural booster" and risk factors. Titres were further analysed in relation to risk factors by multivariate analysis. Statistical significance was set at $\mathrm{p}<0.05$.

The study protocol was approved by the Ethical Committee of the Clinics Hospital of Federal University of Goiás, protocol CEP-150. Informed consent was obtained from the participants at the beginning of the study.

During the six-year post-primary vaccination period, 81 subjects $(47.6 \%)$ were lost to follow-up, primarily due to a change of address with no available information regarding their new addresses. No differences between sex, age or anti-HBs titre following the primary vaccination were observed $(\mathrm{p}>0.05)$ (Table I).

All 89 individuals responded to the hepatitis B vaccination by generating protective anti-HBs titres in 2004; specifically, $1.1 \%$ developed anti-HBs titres of $10-99 \mathrm{mIU} /$
$\mathrm{mL}, 21.3 \%$ of $100-999$ and $77.5 \%$ of $\geq 1.000 \mathrm{mIU} / \mathrm{mL}$. By 2010 , none of these individuals were positive for the anti$\mathrm{HBc}$ marker. Overall, $4.5 \%$ of participants presented with anti-HBs titres of $1-9 \mathrm{mIU} / \mathrm{mL}, 30.3 \%$ of $10-99 \mathrm{mUI} / \mathrm{mL}$, $43.8 \%$ of $100-999 \mathrm{mUI} / \mathrm{mL}$ and $21.3 \%$ of $\geq 1000 \mathrm{mIU} /$ $\mathrm{mL}(\mathrm{p}<0.01)$ (Figure). The anti-HBs GMT values were $236.0 \mathrm{mIU} / \mathrm{mL}$ (95\% CI: 155.65-357.82) in all adolescents, $173.78 \mathrm{mIU} / \mathrm{mL}$ (95\% CI: 93.32-316.22) in females and $295.12 \mathrm{mIU} / \mathrm{mL}$ (95\% CI: 162.18-524.80) in males.

A positive correlation was observed between high anti-HBs titres following the primary vaccination and the values detected six years later $($ Spearman correlation $=$ $0.483 ; \mathrm{p}<0.01)$.

Eleven subjects developed anti-HBs titres higher than two times their previous values, suggesting they had been exposed to HBV (i.e., they received a "natural booster"). Additionally, individuals who reported more than five partners, prostitution, or cocaine use or who had received tattoos/piercings were more likely to have received a natural booster, with prostitution and tattoos/ piercings being significantly associated after the univar-

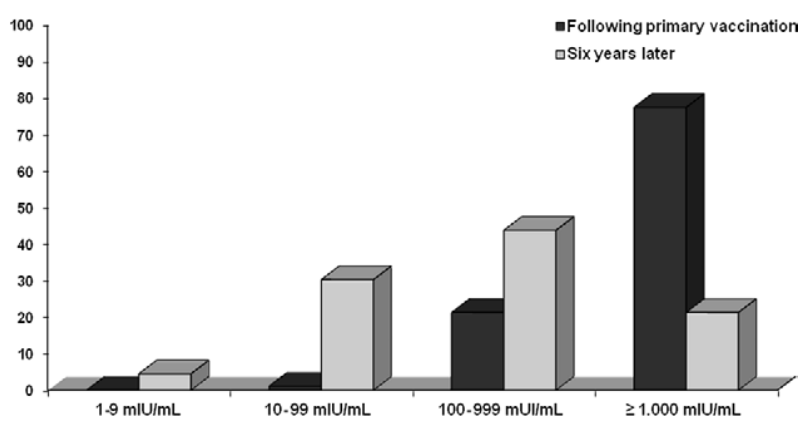

Anti-HBs titres following primary hepatitis B vaccination and six years later in 89 immunisated in 2004, state of Goiás, Central Brazil, 2010.

TABLE I

Characteristics of 170 youths vaccinated against hepatitis B vaccine in 2004, Central Brazil

\begin{tabular}{|c|c|c|c|}
\hline Data & $\begin{array}{l}\text { Participants } \\
\qquad(\mathrm{n}=89) \\
\mathrm{n}(\%)\end{array}$ & $\begin{array}{l}\text { No participants } \\
\qquad \begin{array}{c}(\mathrm{n}=81) \\
\mathrm{n}(\%)\end{array}\end{array}$ & $\mathrm{p}$ \\
\hline \multicolumn{4}{|l|}{ Sex } \\
\hline Female & $38(42.7)$ & $42(51.8)$ & - \\
\hline Male & $51(57.3)$ & $39(48.1)$ & 0.23 \\
\hline \multicolumn{4}{|l|}{ Age $($ years $)($ mean $=21.3)$} \\
\hline$\leq 21$ & $48(53.9)$ & $44(54.3)$ & - \\
\hline$>21$ & $41(46)$ & $37(45.6)$ & 0.96 \\
\hline \multicolumn{4}{|l|}{ Anti-HBs titre (mIU/mL) } \\
\hline Anti-HBs titres $\geq 1.000$ & $69(77.5)$ & $72(88.9)$ & - \\
\hline Anti-HBs titres 100-999 & $19(21.4)$ & $09(11.1)$ & 0.12 \\
\hline Anti-HBs titres 10-99 & $01(1.1)$ & - & \\
\hline Anti-HBs GMT (mIU/mL) $(95 \% \mathrm{CI})$ & $4.031 .8(2908.7-5588.5)$ & $4.713(3467.4-6412.1)$ & - \\
\hline
\end{tabular}

CI: confidence interval; GMT: geometric mean titre. 
iate analysis. Furthermore, these variables were marginally associated with a natural booster following the multivariate analysis: tattoos/piercings $=$ adjusted odds ratio (OR): 4.4 (95\% CI: 0.9-22.3) and prostitution = adjusted OR: 7.0 (95\% CI: 0.8-61.2) (Table II).

This study, for the first time, described data regarding the persistence of anti-HBs following a HBV vaccination using $H$. polymorpha yeast cells as the expression system for the generation of recombinant HBsAg. Furthermore, this recombinant HBsAg, which comprises the Brazilian HBV vaccine, elicited significant levels of protection in sexually active individuals vaccinated six years earlier. None of the youths in the vaccine cohort were infected by HBV, despite the high frequency of risky behaviours in this population. Additionally, as observed for other vaccines (Jilg et al. 1988, But et al. 2008), a positive correlation was observed between high anti-HBs titres after the primary vaccination and the titres observed at follow-up.
Based on the kinetics of the anti-HBs response, a decline in anti-HBs titres occurs over time, rapidly declining within the first year post-vaccination and more slowly thereafter. Generally, $3-30 \%$ of vaccinated individuals lose their protective anti-HBs titres five years after the hepatitis B vaccination. This variability in the response is affected by several factors, including the type of vaccine used, the amount of antigen delivered and the population immunised (Whittle et al. 2002, Nakao et al. 2003, Alfaleh et al. 2008, But et al. 2008, Gilca et al. 2009). However, re-exposure to HBsAg (natural or vaccine) commonly induces a protective antibody response trigged by memory $\mathrm{T}$ cells and $\mathrm{B}$ cells.

In the present cohort, all individuals developed protective anti-HBs titres after receiving a complete vaccination regimen, consisting of a GMT of $4031.8 \mathrm{mIU} / \mathrm{mL}$. Six years after the primary vaccination, anti-HBs could still be detected in all participants; $94.5 \%$ maintained protective anti-HBs antibodies with a GMT of $236 \mathrm{mIU} /$

TABLE II

Variables associated with natural booster in youths vaccinated against hepatitis B over six years, state of Goiás, Central Brazil, 2010

\begin{tabular}{|c|c|c|c|c|}
\hline \multirow[b]{2}{*}{ Variables } & \multicolumn{2}{|c|}{ Natural booster } & \multicolumn{2}{|c|}{ Odds ratio $(95 \% \mathrm{CI})$} \\
\hline & n/total (\%) & Crude & Adjusted $^{a}$ & $\mathrm{p}$ \\
\hline \multicolumn{5}{|l|}{ Sex } \\
\hline Female & $4 / 38(10.5)$ & 1.0 & 1.0 & - \\
\hline Male & $7 / 51(13.7)$ & $1.3(0.4-5.0)$ & $1.6(0.4-7.0)$ & 0.52 \\
\hline \multicolumn{5}{|l|}{ Homosexual activity } \\
\hline No & 10/83 (12) & - & - & - \\
\hline Yes & $0 / 3(0)$ & - & - & - \\
\hline \multicolumn{5}{|l|}{ Condom use } \\
\hline Always & 4/36 (11.1) & 1.0 & - & - \\
\hline Sometimes/never & 6/49 (12.2) & $1.1(0.3-4.3)$ & - & - \\
\hline \multicolumn{5}{|l|}{ Previous STD } \\
\hline No & 11/81 (13.6) & - & - & - \\
\hline Yes & $0 / 5(0)$ & - & - & - \\
\hline \multicolumn{5}{|c|}{ Number of sexual partner } \\
\hline$\leq 5$ & $4 / 45(8.9)$ & 1.0 & - & - \\
\hline$>5$ & $7 / 43(16.3)$ & $2.0(0.5-7.4)$ & - & - \\
\hline \multicolumn{5}{|l|}{ Prostitution } \\
\hline No & 9/83 (10.8) & 1.0 & - & - \\
\hline Yes & $2 / 4(50)$ & $8.2(1.03-65.7)$ & $7.0(0.8-61.2)$ & 0.08 \\
\hline \multicolumn{5}{|l|}{ Prison } \\
\hline No & $11 / 84(13.1)$ & - & - & - \\
\hline Yes & $0 / 5(0)$ & - & - & - \\
\hline \multicolumn{5}{|l|}{ Illicit drug use } \\
\hline Never & $6 / 62(9.7)$ & 1.0 & - & - \\
\hline Marijuana & $2 / 16(12.5)$ & $1.3(0.2-8.7)$ & - & - \\
\hline Cocaine & $3 / 11(27.3)$ & $3.0(0.6-18.2)$ & - & - \\
\hline \multicolumn{5}{|l|}{ Tattoos/piercings } \\
\hline No & $2 / 43(4.7)$ & - & - & - \\
\hline Yes & $9 / 46(19.6)$ & $5.0(1.01-24.6)$ & $4.4(0.9-2.3)$ & 0.07 \\
\hline
\end{tabular}

$a$ : adjusted by age, sex prostitution and tattooing/piercing; CI: confidence interval; STD: sexually transmitted diseases. 
$\mathrm{mL}$. Furthermore, 11 individuals presented with anti-HBs titres at least two-fold higher than their previously recorded values, suggesting natural boosting. A higher proportion of risky behaviours were found in these individuals, reinforcing the "natural boosting" hypothesis, with prostitution and tattoos/piercings statistically associated with "natural booster" exposure following the univariate analysis. Unfortunately, the sample size in the present study was too small to detect a strong association following the multivariate analysis between the antibody titres and these variables. Similar to a previous study, we also observed that the anti-HBs titres decreased less rapidly in men compared with women (McMahon et al. 2005), but this difference was not significant in this study.

Previous work demonstrated a significant association between protective anti-HBs titres (following primary vaccination) and the magnitude of the anamnestic response (Chaves et al. 2010) that gradually declines over time (Chaves et al. 2012), suggesting that elevations in the anti-HBs titres following the primary vaccination would be protective despite a case report describing a previously vaccinated male who was chronically infected with HBV (O'Halloran et al. 2011). The administration of three doses of $20 \mu \mathrm{g}$ of the Brazilian HBV vaccine successfully elicited the production of protective antibodies in high-risk adolescents in GO (Oliveira et al. 2006) and the present study further supports these observations regarding the effectiveness of this vaccine in the medium term.

Today, due to the lower immunogenicity responses to vaccination of individuals 30 years and older, the Brazilian hepatitis B vaccine now consists of $25 \mu \mathrm{g} / \mathrm{mL}$ of recombinant HBsAg and infants and adolescents are immunised with three doses of $12.5 \mu \mathrm{g} / \mathrm{mL}$ at zero, one and six-month intervals (Moraes et al. 2010). This modified formulation needs to be evaluated for its long-term effectiveness among infants and adolescents.

\section{REFERENCES}

Alfaleh F, Alshehr S, Alansari S, Aljeffri M, Almazrou Y, Shaffi, AAbdo AA 2008. Long-term protection of hepatitis B vaccine 18 years after vaccination. $J$ Infect 57 : 404-409.

Beasley RP 2009. Development of hepatitis B vaccine. JAMA 302: 322-324.

But DY, Lai CL, Lim WL, Fung J, Wong DK, Yuen MF 2008. Twentytwo years follow-up of a prospective randomized trial of hepatitis $\mathrm{B}$ vaccines without booster dose in children: final report. Vaccine 26: 6587-6591.

Chaves SS, Fischer G, Groeger J, Patel PR, Thompson ND, Teshale EH, Stevenson K, Yano VM, Armstrong GL, Samandari T, Kamili S, Drobeniuc J, Hu DJ 2012. Persistence of long-term immunity to hepatitis B among adolescents immunized at birth. Vaccine 30: 1644-1649.

Chaves SS, Groeger J, Helgenberger L, Auerbach SB, Bialek SR, Hu DJ, Drobeniuc J 2010. Improved anamnestic response among adolescents boosted with a higher dose of the hepatitis B vaccine. Vaccine 28: 2860-2864.

Gilca V, de Serres G, Boulianne N, de Wals P, Murphy D, Trudeau G, Masse R, Duval B 2009. Antibody kinetics among 8-10 years old respondents to hepatitis $\mathrm{B}$ vaccination in a low endemic country and the effect of a booster dose given 5 or 10 years later. Vaccine 27: 6048-6053.

Hieu NT, Kim KH, Janowicz Z, Timmermans I 2002. Comparative efficacy, safety and immunogenicity of Hepavax-Gene and Engerix-B, recombinant hepatitis B vaccines, in infants born to HBsAg and HBeAg positive mothers in Vietnam: an assessment at 2 years. Vaccine 20: 1803-1808.

Ioshimoto LM, Rissato ML, Bonilha VS, Miyaki C, Raw II, Granovski N 1999. Safety and immunogenicity of hepatitis B vaccine Butang in adults. Rev Inst Med Trop Sao Paulo 41: 191-193.

Jilg W, Schmidt M, Deihrardt F 1988. Persistence of specific antibodies after hepatitis B vaccination. J Hepatol 6: 201-207.

McMahon BJ, Bruden DL, Petersen KM, Bulkow LR, Parkinson AJ, Nainan O, Khristova M, Zanis C, Peters H, Margolis HS 2005. Antibody levels and protection after hepatitis $\mathrm{B}$ vaccination: results of a 15-year follow-up. Ann Intern Med 142: 333-341.

Moraes JC, Luna EJ, Grimaldi RA 2010. Immunogenicity of the Brazilian hepatitis B vaccine in adults. Rev Saude Publica 44: 353-359.

Nakao K, Hamasaki K, Wakihama N, Maeda M, Ohtsubo N, Sagiike T, Ichikawa T, Ishikawa H, Eguchi K, Ishii N 2003. Analysis of anti-HBs levels in healthcare workers over 10 years following booster vaccination for hepatitis B virus. Vaccine 21: 3789-3794.

O'Halloran JA, de Gascun CF, Dunford L, Carr MJ, Connell J, Howard R, Hall WW, Lambert JS 2011. Hepatitis B virus vaccine failure resulting in chronic hepatitis B infection. J Clin Virol 52: 151-154.

Oliveira MDS, Martins RMB, Matos MA, Ferreira RC, Dias MA, Carneiro MAS, Junqueira ALN, Teles SA 2006. Seroepidemiology of hepatitis B virus infection and high rate of response to hepatitis B virus Butang ${ }^{\circledR}$ vaccine in adolescents from low income families in Central Brazil. Mem Inst Oswaldo Cruz 101: 251-256.

Poorolajal J, Mahmoodi M, Majdzadeh R, Nasseri-Moghaddam S, Haghdoost A, Fotouhi A. 2010. Long-term protection provided by hepatitis B vaccine and need for booster dose: a meta-analysis. Vaccine 28: 623-31.

Romano L, Paladini S, Van Damme P, Zanetti AR 2011. The worldwide impact of vaccination on the control and protection of viral hepatitis B. Dig Liver Dis 43 (Suppl. 1): S2-S7.

Shouval D 2003. Hepatitis B vaccines. J Hepatol 39 (Suppl.): S70-S76.

Vijayakumar V, Hari R, Parthiban R, Mehta J, Thyagarajan SP 2004. Evaluation of immunogenicity and safety of Genevac B: a new recombinant hepatitis B vaccine in comparison with Engerix B and Shanvac B in healthy adults. Indian J Med Microbiol 22: 34-38.

Whittle H, Jaffar S, Wansbrough M, Mendy M, Dumpis U, Collinson A, Hall A 2002. Observational study of vaccine efficacy 14 years after trial of hepatitis B vaccination in Gambian children. BMJ 325: 569.

Zhang Y, Ma JC, Qi SX, Wang F, Zhao C, Bi SL 2011. Effectiveness of a Chinese hamster ovary cell derived hepatitis $\mathrm{B}$ vaccine in Chinese rural communities. Vaccine 29: 3905-3908. 